\title{
Ensino Médio - etapa conclusiva de uma educação em crise
}

\section{LUÍS CARLOS DE MENEZES ${ }^{I}$}

$\mathrm{P}$ ROPOSTAS PARA a Educação Básica, que considerem as transformações na vida e no trabalho na sociedade pós-industrial, já não podem ser as mesmas que foram concebidas há algumas décadas. O que foi trabalho de operários é feito hoje por robôs, e funções de organização e inovação já começam a ser atribuídas a sistemas operacionais. São desafios ainda mais difíceis de enfrentar, quando avaliações revelam retrocesso de mais de década no "Ensino Médio", fase escolar assim chamada pela Lei de Diretrizes e Bases da Educação Nacional (LDB), ${ }^{1}$ a despeito de tomá-la como "etapa conclusiva da Educação Básica", mas denominação é problema menor diante das incertezas de nossa educação.

Nesta mesma revista Estudos Avançados, no primeiro ano deste século, fiz considerações sobre por que razão um Ensino Médio de oferta universal precisaria ser compreendido como etapa essencial para a formação para a cidadania de toda a juventude, contraditando certo elitismo saudoso do tempo em que essa escola era privilégio de poucos (Menezes 2001). O objetivo então era corroborar a já referida LDB, promulgada pouco tempo antes, que atribuía ao Ensino Médio prover "preparação básica para o trabalho e a cidadania", com o emprego de "metodologias de ensino e de avaliação" que estimulassem "a iniciativa dos estudantes", facultando às escolas também promover habilitação profissional.

Naquele momento, tratava-se de dar consistência à conclusão da Educação Básica, com iniciativas em que me envolvi, como a elaboração dos Parâmetros Curriculares Nacionais (PCN) e a formulação original do Exame Nacional do Ensino Médio (ENEM). Ao longo da década anterior havia dobrado o número de estudantes com acesso àquela etapa e que continuou crescendo até o presente, juntamente com a ampliação de acesso a todas as demais etapas de escolarização. Tal crescimento numérico, no entanto, em geral esteve desacompanhado da necessária evolução conceitual, como o emprego das pretendidas metodologias participativas. Por isso, a questão que agora se coloca é o que fazer para avançar em face de reconhecidos descompassos, começando por breve histórico de iniciativas e das reações a elas.

Tanto os PCN para o Ensino Médio quanto o ENEM se organizavam em Áreas do Conhecimento, como Linguagens e Códigos, Ciências Humanas, Ciências da Natureza e Matemática que, mesmo sem terem pretendido eliminar ou fundir os diferentes componentes curriculares que compunham o Ensino 
Médio, geraram controvérsias semelhantes às que agora decorrem das reformas educacionais em curso. Na época, há cerca de duas décadas, diferentes publicações procuraram responder a questões como "Por que a reforma do Ensino Médio propõe uma organização em áreas do conhecimento?", ou ainda, "O trabalho por competências não vai promover uma 'superficialização' dos conteúdos?". ${ }^{2}$ Talvez não por acaso, são as mesmas perguntas que têm hoje pautado os debates.

Para ilustrar quão persistente é a controvérsia em torno do caráter do Ensino Médio, vale lembrar que, há cerca de meio século, houve tentativa oficial, por meio de uma lei, ${ }^{3}$ de compor toda formação geral com alguma formação profissional. Mas sem ter essa lei sido seguida de efetivo apoio conceitual ou logístico, ela resultou em desarranjos e disfarces, tanto em escolas públicas quanto em particulares, até ter sido descontinuada, cerca de uma década depois. Também por isso, há razões para se duvidar do acerto da recente proposição do executivo federal modificando a LDB em 2017, inicialmente por meio de Medida Provisória, em seguida transformada em lei, ${ }^{4}$ que entre outras medidas divide aquela etapa escolar em dois períodos, o de formação geral, a que se atribuem $60 \%$ do seu tempo, e outro, com $40 \%$ do seu tempo, dedicados a percursos alternativos que podem ser voltados a áreas de conhecimento ou a alguma formação de caráter profissional.

Alguns dos percursos alternativos aventados nessa lei parecem corresponder a um retorno aos cursos pré-universitários, justificando a designação "Médio", como o antigo Colegial com as modalidades do "Clássico", voltado às carreias denominadas "humanas" ou "sociais", como direito, publicidade ou administração, e do "Científico", por sua vez dividido nas "biológicas" voltadas a carreiras médicas, e "exatas" para carreiras técnicas como engenharia. Por outro lado, os percursos de sentido profissionalizante, além de não especificados na nova lei, também não orientam as escolas sobre como adequá-los, por exemplo, a perspectivas de demanda regional. Só sinalizam a possibilidade de prover tal diversificação por meio de contrato de profissionais de "notório saber", por associação com instituições de ensino profissionalizante ou por meio de educação a distância, aliás única possibilidade para milhares de municípios que contam com uma só escola de nível médio.

Em centros urbanos, tem havido iniciativas de articulação entre escolas regulares e escolas técnicas de nível médio, cujo número também foi ampliado nas últimas décadas, mas nem sempre com a percepção de quanto as transformações tecnológicas estão alterando o mundo do trabalho e produzindo um desemprego estrutural. Garantir oportunidade de trabalho, em pouco tempo, será desenvolver competências para realizar o que máquinas e sistemas não fazem, desenvolvendo critérios práticos, estéticos e éticos. Para que essa compreensão chegue às escolas, será preciso mudar toda uma cultura educacional, o que não se faz meramente por meio de leis. 


\section{A Base Nacional Comum Curricular - Novo ponto de partida?}

É preciso dar contexto às reformulações agora discutidas, que não se resumem a medidas provisórias e modificações em leis, como parte de uma reforma educacional decorrente do Plano Nacional de Educação (PNE) ${ }^{5}$ envolvendo a elaboração de uma Base Nacional Comum Curricular (BNCC). ${ }^{6}$ Para as etapas da Educação Infantil e da Educação Fundamental, a BNCC foi apresentada ao Conselho Nacional de Educação (CNE), discutida em conferências regionais e finalmente oficializada pelo Ministério da Educação. Trata-se de documento de quinhentas páginas, extensão imprópria para uma "base curricular", que mereceria ser sintetizado ou ganhar um documento síntese. ${ }^{7}$ Para o Ensino Médio, ainda não existe uma BNCC, sendo suas versões prévias substituídas por outra concebida nos termos daquela lei, mas com seus componentes não provendo progressão conceitual relativamente aos do Ensino Fundamental, e talvez por isso não acatada.

O Ministério da Educação noticia a elaboração de uma nova versão da BNCC do Ensino Médio, com a pretensão de homologá-la já em 2018, mas, caso ocorra, não se pode descartar a possibilidade de que venha a ser revista, juntamente com a própria lei, em decorrência da transição governamental. A experiência daquela malsucedida lei semelhante, há cinco décadas, sugere a importância de um amplo debate que oriente a reforma, considerando também o que já se explicitou no início deste texto, a transformação no conceito de trabalho na sociedade pós-industrial.

Um mérito da parte da BNCC já conhecida é indicar objetivos gerais e específicos de aprendizagem, denominados na última versão como "competências" e "habilidades", envolvendo qualificações pessoais e valores humanos não passivamente absorvidos e sim desenvolvidos em práticas coletivas ou individuais. O sentido geral de qualificar para pensamento crítico, para protagonismo e para condutas solidárias está na direção correta nos objetivos gerais, mas tal intenção se apresenta tão dividida nas habilidades entre vários componentes, que falta centralidade na formação de cada estudante. Também por isso, uma revisão conjunta da BNCC para toda a Educação Básica produziria maior articulação entre as etapas em um melhor documento único que se beneficie de contribuições das versões anteriores, como será brevemente apontado a seguir.

A BNCC para a Educação Infantil está apresentada em função de direitos como brincar e conviver, e de campos de experiência como os de percepção e de comunicação, podendo ser sintetizada em tais termos. Já a BNCC para os primeiros cinco anos da Educação Fundamental está desnecessariamente fracionada em nove extensos componentes, quando se sabe que, usualmente, todos serão conduzidos por uma única educadora polivalente ou por um par de educadoras, portanto haveria grande vantagem em articular os componentes, organizando-os por fase ou ciclo e, sinteticamente, combinando-os com o domínio da escrita e da matemática presente em todos eles e essencial nessa etapa escolar. 
Já para os quatro anos finais da Educação Fundamental, esses deveriam, na BNCC, ser tratados em continuidade com o Ensino Médio, seja por seus componentes serem praticamente os mesmos, seja por seus professores também serem os mesmos. O que está feito para os anos finais da Educação Fundamental peca pelo excessivo detalhamento, ou até pela prolixidade e redundância, mas se constituiria em um bom ponto de partida para um exercício de síntese e de subsequente formulação para o Ensino Médio.

Algumas boas características encontradas em alguns componentes poderiam ser generalizadas, por exemplo para a Matemática, que está apresentada ainda muito pobre de contextos; poderia ser inspiradora a boa contextualização das atividades encontradas nas Ciências da Natureza e nas Ciências Humanas, o que lhes dá mais significado e propicia atividades coletivas e individuais de estudantes, participando de projetos de interesse real. Vale insistir que envolvimento de estudantes em projetos práticos, nos quais eles encontrem suas propensões e vislumbrem seus projetos de vida, não se constitui em atividade extracurricular, mas em parte integrante necessária da conclusão de sua educação.

Mesmo admitindo a importância que uma boa BNCC poderá ter para o aperfeiçoamento da aprendizagem, é preciso reconhecer que ela é mera base para um trabalho que a transcende, especialmente quando consideramos o péssimo desempenho da Educação Básica revelado nas avaliações gerais. Aliás, de pouco adiantam as inúmeras formas com que se verificam as condições lamentáveis de nossa Educação, se não forem tomadas como diagnósticos que devam dar lugar a prognósticos e proposições capazes de superar deficiências encontradas. É o que brevemente se pretenderá mostrar a seguir.

\section{Diagnósticos e propostas}

Os últimos resultados de uma avaliação escolar nacional, ${ }^{8}$ mostram um Ensino Médio estagnado ou piorando há mais de década, o que está sendo anunciado com grande repercussão pelo Ministério da Educação, ainda que como diagnóstico sem alternativas efetivas de enfrentamento. Acrescente-se que, ao mau desempenho soma-se em certas regiões taxa de reprovação e abandono de mais de metade das turmas, por razões pedagógicas e econômicas que precisam ser bem compreendidas para dar lugar a correções.

Não se deve, no entanto, julgar isoladamente o Ensino Médio, sem considerar heranças da escola que o antecede, cuja fragilidade é igualmente atestada por avaliações escolares gerais e exames nacionais que mostram a ineficácia da alfabetização e do domínio da matemática de estudantes do Ensino Fundamental, boa parte dos quais terminam essa etapa sem proficiência em leitura e cálculo, assim como do despreparo geral da população que já frequentou a escola, mostrado pelo Indicador de Alfabetismo Funcional (INAF) ${ }^{9}$ e pelo Indicador de Letramento Científico (ILC) ${ }_{1}^{10}$ que apontam dezenas de milhões de analfabetos funcionais entre os egressos da escola e mostram somente $10 \%$ da população que passou pelo Ensino Superior com letramento científico proficiente. 
A extensão desses problemas reclama iniciativas para recompor a Educação Básica como um todo, como se sinalizou nas sugestões relativas à BNCC, assim como de outras políticas, como se procurará meramente esboçar a seguir. Uma advertência quando se elaboram propostas para reformular o ensino é que diretrizes, parâmetros e bases curriculares não são mais do que meras recomendações, se desacompanhadas de políticas correspondentes de provisão de recursos materiais e humanos, com metas e prazos para seu acompanhamento, identificando e apoiando responsáveis por sua efetivação.

Por exemplo, sabendo que entre as fragilidades a serem superadas estão a oferta insuficiente da Educação Infantil e a ineficácia da alfabetização, podem se identificar os municípios como efetiva e legalmente responsáveis por essas etapas. Mas muitos municípios além de terem baixo orçamento próprio, também são os menos agraciados pelos recursos fiscais, majoritariamente divididos entre a Federação e os Estados. Portanto, entre as políticas para educação infantil e alfabetização precisa constar a maior transferência de recursos para os municípios.

Isso, no entanto, é condição inicial que não basta, uma vez que o necessário aperfeiçoamento educacional envolve formação em serviço dos nossos dois milhões e meio de professores, a maioria dos quais trabalha para municípios, que geralmente os remunera ainda menos e não têm condições de prepará-los melhor. Eis uma tarefa que deve ser assumida pelos estados, com cursos semipresenciais, em que grupos de professores reunidos em escolas acompanhem programas a distância com projeções de boas práticas, acompanhados por professores-tutores da região, selecionados em função da excelência de seu desempenho profissional e remunerados para tais ações.

Há um duplo pressuposto nessa última sugestão: primeiro, que os professores são personagens-chave, sem os quais não se conduz nem se aperfeiçoa a Educação Básica; segundo, que os professores também se formam nas escolas, ou seja, no exercício partilhado e supervisionado de sua atuação profissional. Levar isso em conta, tanto para formação continuada quanto para formação inicial, pode dar lugar a recomendações de significado essencial, tanto para o processo formativo quanto para a carreira dos professores, como se vai agora tentar sinalizar.

Há hoje uma tácita compreensão de que professores se formam em faculdades e que só depois de formados vão exercer suas profissões em escolas, algo como desconsiderar que o magistério é uma profissão, como a de um piloto ou um pediatra, que precisa ser aprendida em seu exercício. Há ainda a tácita compreensão de que o progresso na carreira dos professores se efetiva quando se tornam coordenadores pedagógicos ou quando assumem qualquer outra função na escola ou no sistema escolar, ou seja, quando deixam de trabalhar como professores. Tudo isso contrariando os pressupostos mencionados há pouco.

Se, pelo contrário, aqueles pressupostos fossem considerados, professores se formariam não somente em faculdades, mas também trabalhando em escolas, 
sob supervisão de professores experientes, escolhidos como tutores por conta de sua excelência profissional. Esses tutores estariam em uma etapa de suas carreiras em que se dividiriam em duas diferentes tarefas, uma seria continuar a ensinar seus estudantes, outra seria supervisionar futuros colegas ou atuais colegas, em sua formação inicial ou em sua formação continuada em serviço. Poderiam ter feito uma especialização para isso, mas teriam sido selecionados por competência e seriam parcialmente remunerados por seu trabalho como formadores. Ou seja, carreira de professor não seria mais deixar de ser professor.

Se ao longo do próximo ano tivermos elaborado e aprovado uma BNCC completa, que indique como nossas escolas deveriam garantir, como propõe a LDB para o Ensino Médio, uma "preparação básica para o trabalho e a cidadania", com o emprego de "metodologias de ensino e de avaliação que estimulem a iniciativa dos estudantes", essa será base também para a preparação de mais de meio milhão de professores atuando nessa etapa educacional e na do fundamental avançado.

Para promover sua formação em serviço, não haveria como nem por quê trazê-los de volta às mesmas faculdades em que se formaram, e sim estabelecer a nova carreira de professores, em que aqueles que tenham excelência profissional se tornem tutores e formadores de seus colegas e futuros colegas, trabalhando em suas escolas NÃO APENAS. Isso seria parte de um grande esforço nacional para construir a Educação Básica de que precisamos. Outra iniciativa, aliás, seria desenvolver vida cultural, social e desportiva nessas escolas de nível fundamental avançado e médio, envolvendo estudantes e professores, esses necessariamente vinculadas a uma única escola.

Em síntese, sugere-se: 1 garantir apoio logístico e melhor distribuição dos recursos fiscais para os municípios conduzirem a Educação Infantil e o início da Educação Fundamental; 2 elaborar uma base curricular nacional completa e sintética, que oriente anos finais do Ensino Fundamental e o Ensino Médio para serem mais articulados e significativos, e prover suas escolas de ampla vivência cultural e social; 3 estabelecer nova carreira de professores, para que progridam tornando-se tutores e formadores, em associação com o trabalho das faculdades.

Isso tudo pode parecer de difícil execução e há quem duvide da possibilidade de se pôr em prática ideias como essas, que pretendam fazer das escolas ambientes estimulantes para estudantes orientados por professores motivados. É possível contraditar os descrentes, mostrando como países em condições mais difíceis do que as nossas foram capazes de transformar suas escolas. Já para quem tiver foco no desempenho global da nação, pode-se argumentar que a transformação de nossa escola é condição necessária para o Brasil se reencontrar com seu desenvolvimento social, cultural e econômico, pois sua atual condição de mero exportador de matérias-primas e importador de bens industrializados e serviços chega a constituir um recuo de décadas em termos de sua participação no concerto econômico mundial. Mas talvez o indicador mais preocupante dessas per- 
das nos últimos tempos seja a parte de nossa juventude desencantada querendo deixar o Brasil, levando consigo em sua emigração por desalento a esperança e coragem de que qualquer nação necessita.

\section{Notas}

l Lei n.9.394 de dezembro de 1996, que estabelece as diretrizes e bases da educação nacional.

2 Veja-se, por exemplo, Maia e Carneiro (2000) que explicitam na própria capa tais questionamentos, e os respondem de forma que seria atual ainda hoje.

3 Lei n.5692 de agosto de 1971, uma dessas medidas oficiais cujos resultados foram discutíveis, não tendo por isso tido continuidade.

4 Lei n.13.415 de fevereiro de 2017, promulgada como Conversão da Medida Provisória n.746, de 2016, alterando a LDB.

5 O PNE em 2014 determinou diretrizes, metas e estratégias para a política educacional dos próximos 10 anos.

6 Disponível em: <http://basenacionalcomum.mec.gov.br>.

$7 \mathrm{O}$ autor deste artigo produziu um libreto (Menezes, 2018) para orientar sua implementação, mas sem a pretensão de constituir a necessária síntese sugerida.

8 Ver Sistema de Avaliação da Educação Básica (Saeb) 2017, disponível em: <http:// provabrasil.inep.gov.br>.

9 Disponível em: <acaoeducativa.org.br>.

10 Publicado em Gomes (2015).

\section{Referências}

GOMES, A. S. L. (Org.) Letramento científico: um indicador para o Brasil. São Paulo: Instituto Abramundo, 2015.

MAIA, E.; CARNEIRO, M. A Reforma do Ensino Médio em questão. São Paulo: Biruta, 2000 .

MENEZES, L. C. de. O novo público e a nova natureza do Ensino Médio. Estudos Avançados, v.15, n.42, p.202-8, 2001.

BNCC de Bolso. São Paulo: Editora do Brasil, 2018.

RESUMO - Associa-se o desempenho do Ensino Médio, estagnado há mais de década, ao conjunto de insuficiências da Educação de Base. Cogita-se a necessidade de se rever recente lei que altera a $\mathrm{LDB}$, assim como de se reelaborar em seu conjunto a Base Nacional Comum Curricular, para poder ser sintética e efetiva referência educacional. Sugere-se melhor distribuição dos recursos fiscais e apoio logístico aos municípios para que possam de fato responder pelo início da escolarização. Propõe-se uma carreira em que professores possam progredir sem deixar de lecionar, tornando-se tutores na formação prática de futuros colegas. 
PALAVRAS-CHAVE: Ensino Médio, Educação Básica, Base Curricular, Carreira de professores.

ABSTRACT - Senior high school performance, stagnated for more than ten years, is related to a general insufficiency of basic education. A recent law that changes the national education law needs to be reviewed together with the common core curriculum in order to become a synthetic educational reference. Better distribution of tax revenues is suggested, as well as logistical support to the counties, so that they can really be held accountable for primary schooling. A teachers' career program is proposed so that they may progress without ceasing to teach, and become tutors in the practical training of futures colleagues.

KEXWORDS: Senior high school, Basic education, Common core curriculum, Teachers' career.

Luis Carlos de Menezes é professor sênior do Instituto de Física e integrante da Cátedra Educação Básica do Instituto de Estudos Avançados na Universidade de São Paulo. @ - menezes@if.usp.br

Recebido em 3.9.2018 e aceito em 24.9.2018.

I Instituto de Física, Universidade de São Paulo, São Paulo, São Paulo, Brasil. 